\title{
CANAIS SECRETORES EM VOCHYSIA THYRSOIDEA POHL (VOCHYSIACEAE) ${ }^{1}$
}

Therezinha Isaia Paviani ${ }^{2}$ Alessa Senna Jeronymo ${ }^{3}$

Recebido em 15-7-91. Aceito em 10-7-92.

RESUMO: Estudou-se a ocorrência de canais secretores de goma nos orgāos vegetativos de Vochysia thyrsoidea Pohl, planta nativa dos cerrados do Brasil Central. Nos estágios iniciais do desenvolvimento, a espécie possui uma tuberosidade formada pelo hipocótilo e pela parte superior da raiz principal. O xilema secundário da parte hipocotilar da tuberosidade apresenta áreas parenquimáticas e canais secretores de goma. Discute-se a possível relaçāo ontogenética entre as áreas parenquimáticas e os canais de goma. Questiona-se a origem traumática dos canais.

Palavras-chave : Vochysia thyrsoidea, canais de goma.

ABSTRACT - The occurrence of gum ducts in the vegetative organs of Vochysia thyrsoidea Pohl, a native plant from the "cerrado" vegetation of central Brazil was studied. This species presents a swollen structure, which forms from the hypocotyl and the upper part of the primary root during the early stages of development. The secondary xylem of the hypocotyl part of the swollen structure shows the presence of both parenchymatic zones and gum ducts. The possible ontogenetic relationship between the parenchymatic zones and the gum ducts is discussed in this paper. The traumatic origin of the gum ducts is questioned.

Key words : Vochysia thyrsoidea, gum ducts.

\section{Introdução}

Vochysia thyrsoidea Pohl é árvore muito comum no cerrado do Distrito Federal, chegando a atingir 12 metros de altura.

1 - Trabalho apresentado no XLI Congresso Nacional de Botânica, Fortaleza - CE.

2 - Departamento de Botânica, Instituto de Ciências Biológicas, Universidade de Brasília. 04631. 70919-970, Brasília, DF.

3 - Bolsista de Iniciaçāo Científica do CNPq. 
A espécie possui, no seu sistema subterrâneo, uma tuberosidade formada pelo hipocótilo e parte superior da raiz principal, a qual se enquadra na categoria de "tubérculo inicial" (Rizzini, 1965).

Um dos nomes vulgares da planta é gomeira, por secretar uma goma similar à goma arábica (Mattos Filho \& Rizzini, 1960/1961). O principal componente da goma é o gomato de manganês e, em menor quantidade, o gomato de potássio, de acordo com análise efetuada no Instituto Agronômico de Campinas (apud Heringer \& Ferreira, 1974).

A goma se forma no interior de canais secretores os quais, no estágio adulto, parecem ser lisígenos, embora não se tenha feito o estudo ontogenético.

A localização dos canais, alguns aspectos da sua formação e a natureza traumática são abordados neste trabalho.

\section{Material e métodos}

Observou-se material em diferentes estágios de desenvolvimento, desde plântulas até indivíduos adultos. $\mathrm{O}$ material em estágio de plântula está registrado no Herbário do Departamento de Botânica da Universidade de Brasília (UB): M. Haridasan 509.

Os materiais em estágios posteriores de desenvolvimento, coletados no Distrito Federal, também estão registrados no Herbário do Departamento de Botânica da Universidade de Brasília (UB), com os seguintes números de coleta : Ieda L. S. C. Paixão 17; M. Haridasan 33 e M. Haridasan 49.

Os indivíduos coletados possuem as seguintes alturas : $3 \mathrm{~cm}$ (plântula), $5 \mathrm{~cm}$, $17 \mathrm{~cm}, 117 \mathrm{~cm}$ e $300 \mathrm{~cm}$. Do exemplar adulto $(300 \mathrm{~cm})$, coletaram-se apenas folhas.

As lâminas, para a observação microscópica, foram preparadas a partir da raiz principal, da tuberosidade, do caule aéreo e das folhas.

O material foi fixado em FAA, emblocado em parafina, cortado em micrótomo rotativo Spencer e corado com azul-de-astra e fucsina-básica; usou-se também a dupla coloração safranina e "fast-green". O material muito lignificado foi cozido em autoclave e cortado em micrótomo para madeira Jung. Fez-se a montagem em resina sintética e as micrografias foram feitas em fotomicroscópio Zeiss.

\section{Resultados e Discussão}

Os canais secretores de goma (Mattos Filho \& Rizzini 1960/1961) estão presentes em todos os orgãos vegetativos e se formam no xilema secundário da tuberosidade, da raiz principal e do caule aéreo. $O$ caule aéreo possui também canais secretores na medula (região perimedular). Nas folhas, os canais estão localizados no pecíolo e na nervura principal da lâmina foliar. Os cortes longitudinais confirmam tratar-se de canais (Figura 1).

A presença de canais secretores na região perimedular do caule aéreo sucita a discussão sobre a origem procambial ou não desses canais, a exemplo do que refere 
Milanez (1946) para os canais secretores do marupá (Simaruba amara Aubl.), presentes tanto na estrutura primária como na secundária. Somente um minucioso estudo ontogenético pode elucidar a verdadeira origem dos "canais medulares" de Vochysia thyrsoidea. Excetuando-se os canais da medula e os das folhas, é evidente a formação dos demais canais no xilema secundário.

Quanto à porção hipocotilar da tuberosidade, na fase de plântula e na estrutura jovem, até aproximadamente $1,5 \mathrm{~cm}$ de diâmetro, os canais estão ausentes, ocorrendo apenas áreas parenquimáticas no xilema que podem ser precursoras dos canais (Figura 2), embora já exista, nesta fase, um câmbio vascular incipiente.

Mattos Filho e Rizzini (1960/1961), estudando a madeira de $V$. thyrsoidea, referem-se à presença de canais de goma dispostos em anel e manchas de parênquima apotraqueal isoladas no tecido fibroso do xilema.

A partir de 2,5 cm de diâmetro, a parte hipocotilar da tuberosidade apresenta canais em anel (Figura 3). Os canais possuem forma e diâmetro variados e tendem a fusionar-se longitudinalmente, formando um único e longo canal (Figura 4).

Sobre a formação dos canais na porção hipocotilar da tuberosidade foram levantadas algumas hipóteses :

1 - Observou-se a presença de anéis nos quais ocorrem áreas parenquimáticas e canais secretores no mesmo anel (Figura 5). Fahn (1979), referindo-se aos ductos de goma traumáticos, cita que nas plantas que os possuem o câmbio vascular forma grupos especiais de células parenquimáticas em lugar dos elementos normais do xilema e o autor relaciona a formação do parênquima aos canais. Pode-se supor então que as áreas parenquimáticas são precursoras dos canais e as que permancecem parenquimáticas podem ter a sua diferenciação interrompida, por fator(es) desconhecido(s).

2 - Em outros cortes da mesma estrutura, verificou-se a presença de anéis de áreas parenquimáticas situados mais internamente aos anéis de canais secretores (Figura 6). Metcalfe e Chalk (1950), fazem referência a canais traumáticos para o gênero Vochysia; considerando-se esses canais como traumáticos, pode-se admitir que as áreas parenquimáticas internas não formam canais por estarem, dada a sua posição, protegidas de possíveis efeitos traumáticos indutores dos canais. No entanto, esta hipótese fica invalidada pela observação de anéis de canais situados mais internamente em relação aos anéis de áreas parenquimáticas (Figura 7).

3 - Observou-se a presença de canais secretores muito próximos ao câmbio vascular, em região ainda não totalmente diferenciada, o que faz supor que as áreas parenquimáticas têm uma diferenciação precoce ou que não são necessariamente precursoras dos canais. Quanto à diferenciação precoce das áreas parenquimáticas, a Figura 2 evidencia esta possibilidade.

A provável relação ontogenética entre as áreas parenquimáticas e os canais secretores necessita ser melhor estudada, observando-se material proveniente da germinação de sementes e seguindo-se, cuidadosamente, as fases iniciais de formação das estruturas.

A parte radicular da tuberosidade dos indivíduos estudados não possui canais, nem áreas parenquimáticas no xilema (Figura 8). 

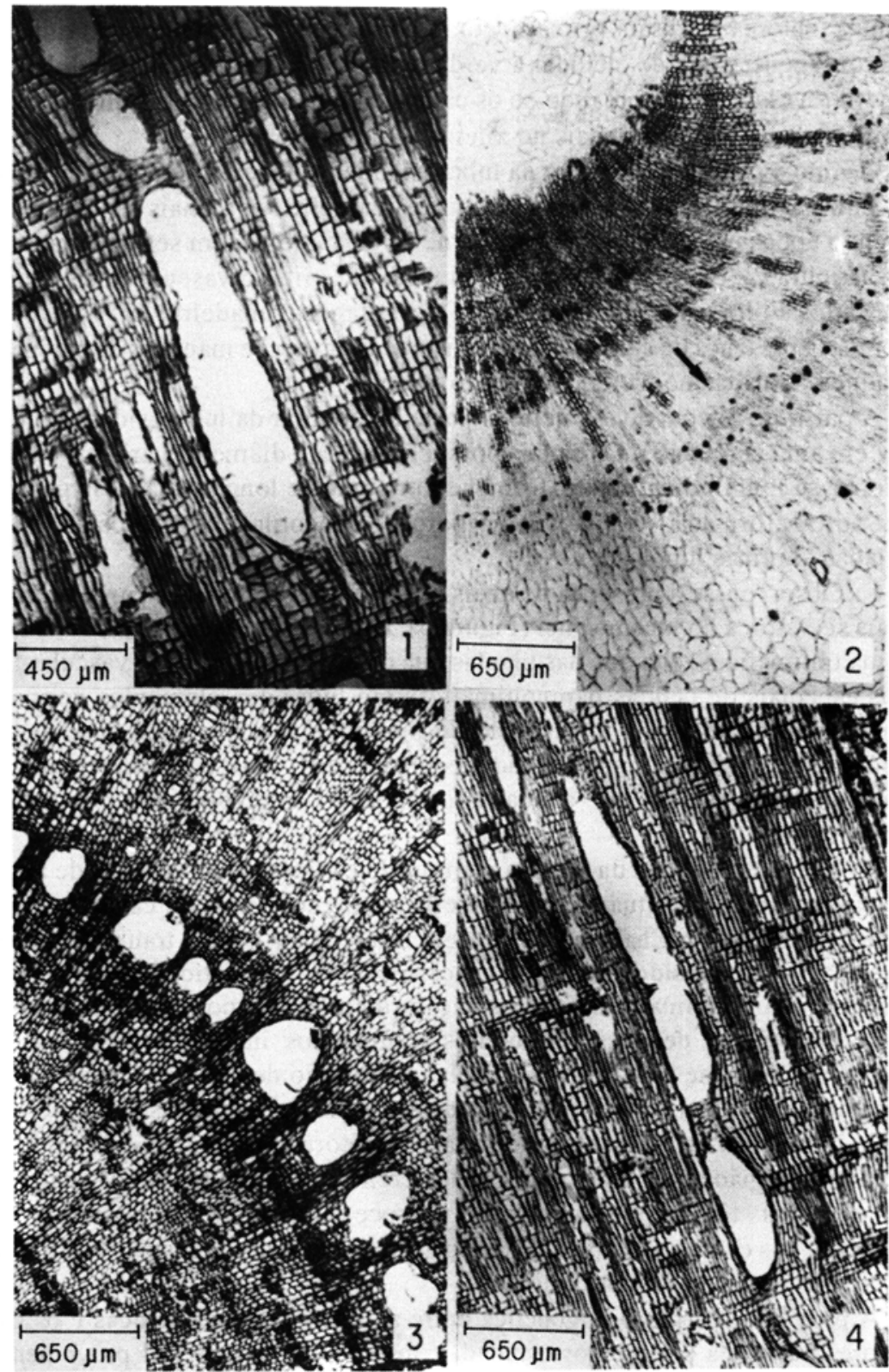

Figuras 1-4 - 1 e 4, cortes longitudinais (caule aéreo); 2e3, cortes transversais (porçāo hipocotilar da tuberosidade). 1 - Canal secretor. 2 - Áreas parenquimáticas (seta) no xilema. 3 - Canais em anel, no xilema. 4 - Canais fusionados. 

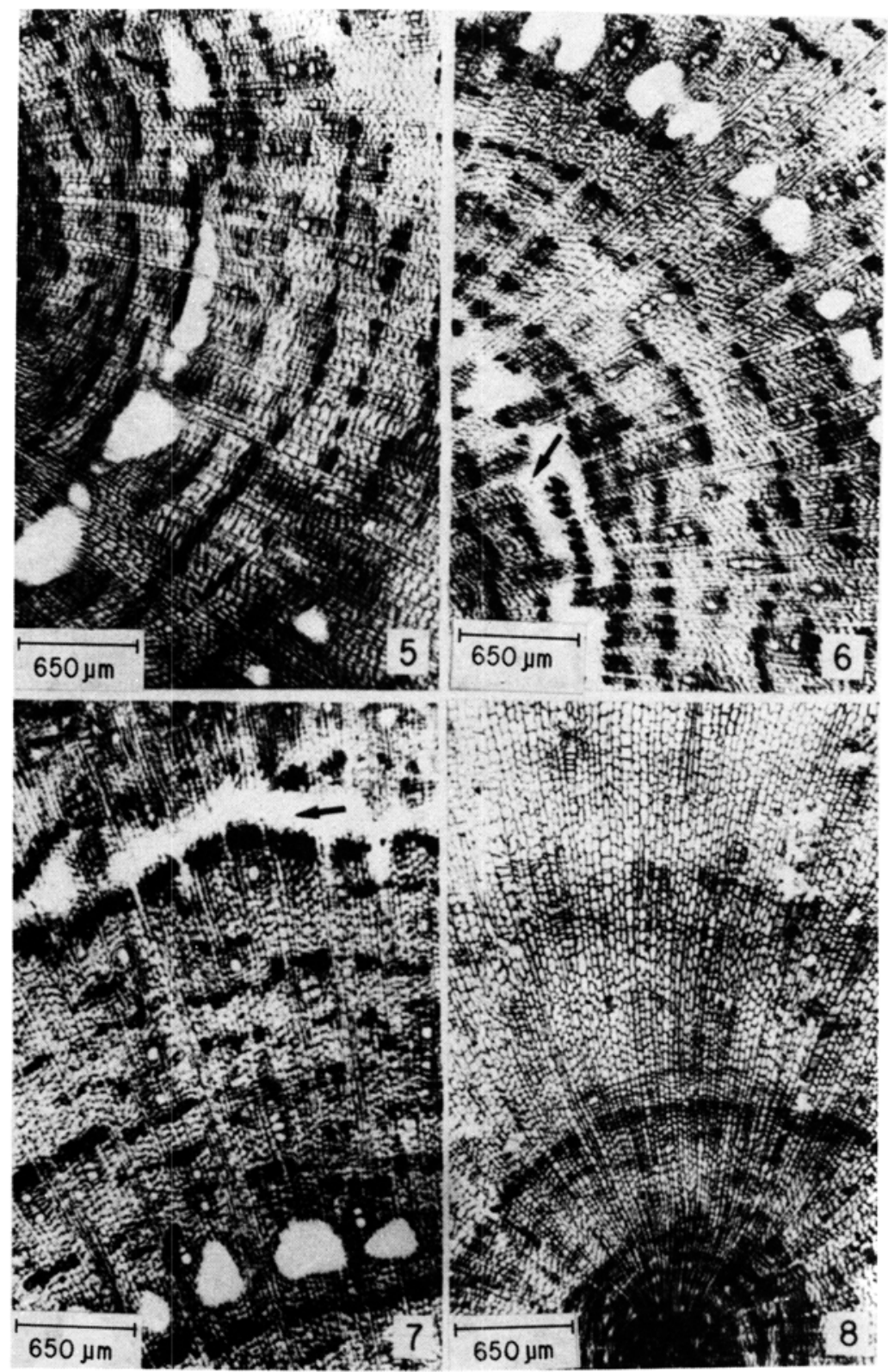

Figuras 5-8 - Cortes transversais. 5, 6 e 7, porçāo radicular da tuberosidade; 8, porçāo radicular da tuberosidade. 5 - Área parenquimática (seta) e canais no mesmo anel. 6 - Anel mais interno de áreas parenquimáticas (seta) e anel mais externo de canais. 7 - Anel mais interno de canais e mais externo de áreas parenquimáticas (seta). 8 - Ausência de canais. 


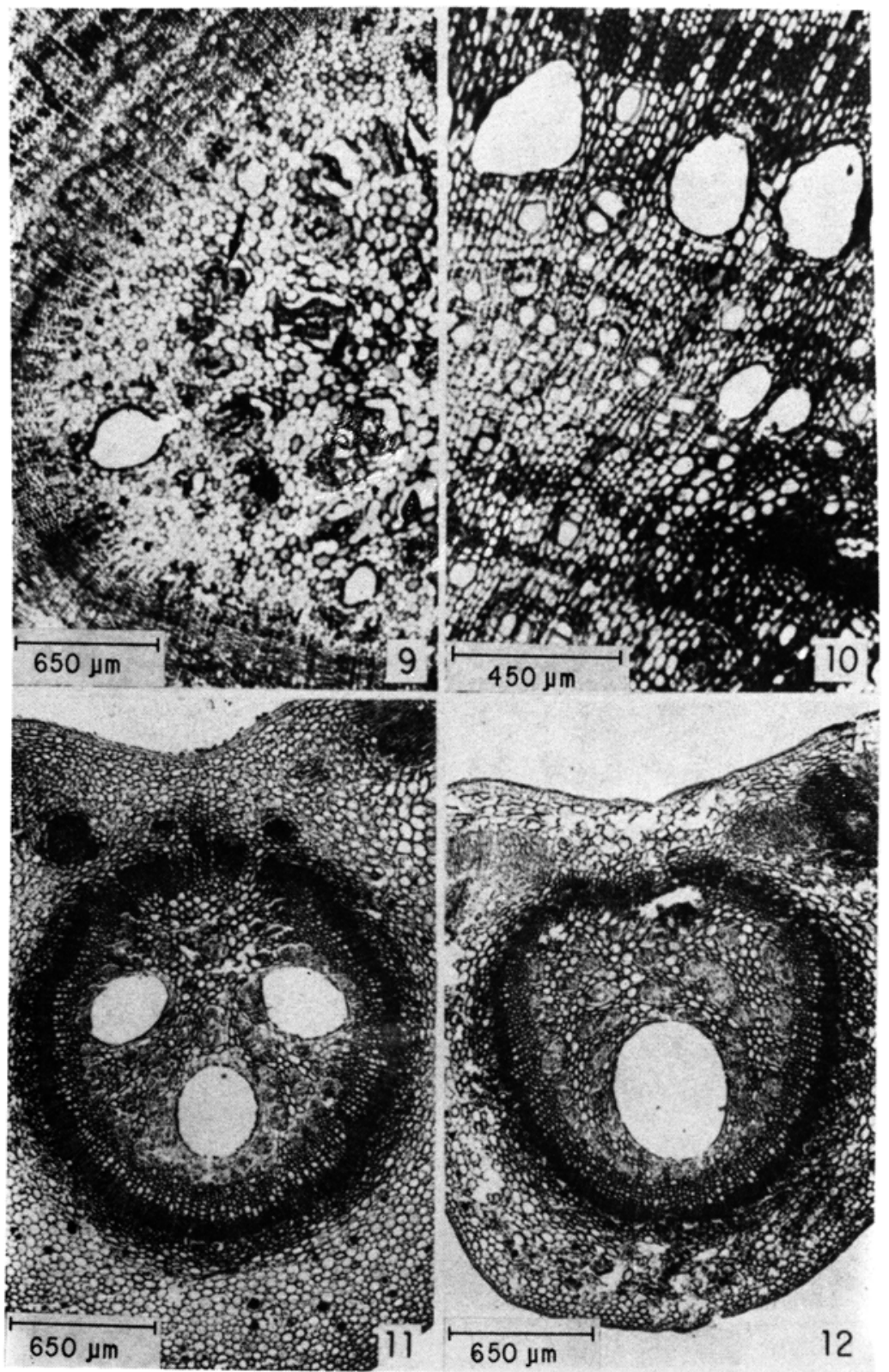

Figuras 9-12 - Cortes transversais. 9 e 10, caule aéreo; 11 e 12, lâmina foliar. 9 - Canais e feixes vasculares (seta) na medula. 10 - Canais no xilema secundário. 11 e 12 - Canais na nervura principal. 
Abaixo da tuberosidade, na raiz principal de menor desenvolvimento, o xilema não possui canais e nem áreas parenquimáticas. Em raízes maiores, de 4,7 cm de diâmetro, nota-se a formação de canais mas não foi constatada a presença de áreas parenquimáticas.

Como já foi referido, no caule aéreo há canais na região perimedular e feixes vasculares formados na sua maioria por floema, imersos na medula (Figura 9). Os canais ocorrem também no xilema secundário (Figura 10).

No pecíolo, o número de canais varia de um a três. Em plântulas, não há canais na lâmina foliar. Em folhas adultas, os canais estão presentes na nervura central, podendo aparecer até três canais na base da lâmina foliar (Figura 11) e apenas um, no terço médio (Figura 12). No ápice foliar não há canais secretores. A presença de canais na nervura central da folha de $V$. thyrsoidea foi referida por Maria \& Ferreira (1972).

Quanto à citação de Metcalfe e Chalk (1950), segundo a qual ocorrem canais traumáticos no gênero Vochysia, cabe uma discussão e uma indagação sobre o assunto. A simples produção de goma já caracteriza o canal traumático? Esta pergunta decorre do fenômeno da degenerescência gomosa. Podem ser traumáticos canais que se apresentam largamente distribuídos e dispostos de maneira tão ordenada? Estas questões devem ser aprofundadas.

Os canais gomíferos de $V$. thyrsoidea não parecem ser traumáticos, pelo menos no que concerne à causas mecânicas. Quanto a fatores químicos, o etileno pode atuar sobre as células induzindo a síntese de enzimas hidrolíticos nas células do xilema, os quais dissolvem a lamela média e formam o lume do canal (Gedalovich e Fahn, 1985).

\section{Referências bibliográficas}

FAHN, A. 1979. Secretory Tissues in Plants. Academic Press, London.

GEDALOVCH, E. \& A.FAHN. 1985. Ethylene and gum duct formation in Citrus. Annals of Botany, 56: 571-577.

HERINGER, E. P. \& M. B. FERREIRA. 1974. Árvores úteis da região geoeconômica do DF. Pau de tucano, Vinheiro, etc. Gênero Vochysia. Cerrado, 6(24): 21-28.

MARIA, J. \& M. B. FERREIRA. 1972. Estudos sobre Vochysiaceae IV. Contribuição ao conhecimento de Vochysia thyrsoidea Pohl. Oréades 3(5): 30-37.

MATTOS FILHO, A. \& C. T. RIZZINI 1960/1961. Contribuição ao estudo de Vochysia thyrsoidea Pohl. Rodriguésia, 35 e 36 : 83-90.

METCALFE, C. R. \& L. CHALK 1950. Anatomy of the Dicotyledons. Vol I. Clarendon Press, Oxford.

MILANEZ, F. R. 1946. Canais secretores do marupá. Rodriguésia, ano x, 20: 13-40.

RIZZINI, C. T. 1965. O xilopódio e outros orgãos tuberosos de plantas do Cerrado. An. Acad. brasil. Ciênc. 37(1): 87-113. 